Portland State University

PDXScholar

\title{
An Empirical Study of the Impacts of Bicycles on Passenger Car Speeds on Urban Roads without Bicycle Lanes
}

\author{
Jaclyn S. Schaefer \\ Portland State University, jsschae@pdx.edu \\ Miguel Figliozzi \\ Portland State University, figliozzi@pdx.edu \\ Avinash Unnikrishnan \\ Portland State University, uavinash@pdx.edu
}

Follow this and additional works at: https://pdxscholar.library.pdx.edu/cengin_fac

Part of the Transportation Engineering Commons

Let us know how access to this document benefits you.

\section{Citation Details}

Schaefer, Jaclyn S.; Figliozzi, Miguel; and Unnikrishnan, Avinash, "An Empirical Study of the Impacts of Bicycles on Passenger Car Speeds on Urban Roads without Bicycle Lanes" (2020). Civil and Environmental Engineering Faculty Publications and Presentations. 575.

https://pdxscholar.library.pdx.edu/cengin_fac/575

This Pre-Print is brought to you for free and open access. It has been accepted for inclusion in Civil and Environmental Engineering Faculty Publications and Presentations by an authorized administrator of PDXScholar. Please contact us if we can make this document more accessible: pdxscholar@pdx.edu. 


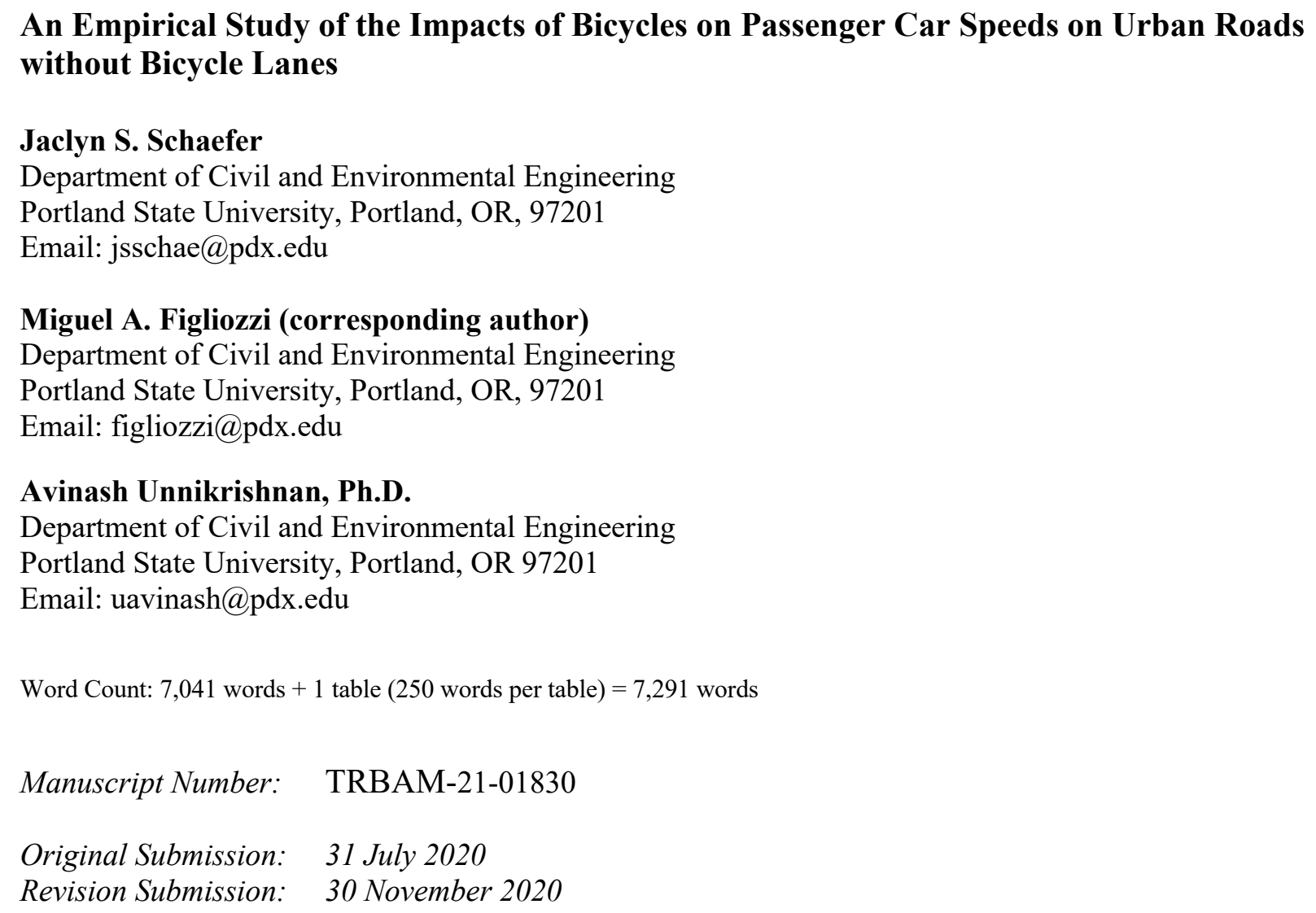

Paper accepted for presentation at the 2021 TRB Annual Meeting (January 2021, Washington DC) and potential publication in Transportation Research Record. 
1

2

\begin{abstract}
Higher bicycle mode share has been suggested as part of a solution to reduce the burden of congestion in urban areas. As strategies to promote bicycling are implemented, concerns have been raised by some road users and stakeholders citing simulation based traffic studies that indicate that an increase in the bicycle mode share generates major travel time delays via reduced vehicle speeds unless bicycle lanes are provided. The current research investigates the effects bicycles may have on motorized vehicle speeds on a variety of lower speed and volume urban roads without bicycle lanes. A detailed comparative analysis of passenger car speeds was performed using two vehicle scenarios: (i) a passenger car that was preceded by a bicycle, and (ii) a passenger car that was preceded by another passenger car. The mean and $85^{\text {th }}$ percentile speeds of scenarios (i) and (ii) were analyzed using $t$-tests. Relationships between speed and gap times with oncoming (opposite direction) traffic were also investigated. The results indicate that at most sites $(92 \%)$, bicycles do not reduce passenger car mean speeds by more than $1 \mathrm{mph}$. Speed reductions are not generally observed in local streets or facilities with adequate numbrer of gaps in oncoming traffic for overtaking.
\end{abstract}

Keywords: Urban, shared, local, collector, vehicle speed, bicycle speed, mixed-traffic, overtaking 
Schaefer, Figliozzi, and Unnikrishnan

\section{INTRODUCTION}

Over $76 \%$ of workers in the U.S. commute by single-occupancy vehicles [1]. Combined with rising populations and increasing urbanization, traffic congestion and travel time delay are perpetually growing problems in many cities. In response, solutions, such as encouraging cycling, are being sought to help reduce the use of single-occupancy vehicles. Cycling is typically regarded as a healthy and environmentally friendly form of transportation. Proponents tout its potential role in reducing greenhouse gas emissions, in addition to mitigating traffic congestion. As such, initiatives to promote cycling for transportation have been pushed by cities and cycling advocates in recent years to increase the bicycle mode share.

Across the U.S., bicycling is a highly underutilized mode of transportation, with less than $1 \%$ of the commute mode share, on average [1]. Even in cities such as Portland, Oregon, where $6.3 \%$ of workers commuted by bicycle in 2017 [2], there is a huge opportunity to increase bicycle ridership. Portland is renowned throughout the U.S. for its cycling culture. The City continues to push forward projects to build a safe and well-connected network of bicycle facilities in hopes of reaching a $25 \%$ bicycle mode share by the year 2030 [3]. As of 2019, there were 385 miles of bikeways in Portland. Shared roads are an integral component of this network, constituting $27 \%$ of the bikeway miles [2].

While it is generally preferred to segregate motor vehicles and bicycles by providing designated lanes, creating a separate infrastructure on every road is infeasible and often unnecessary. For example, roadways with speed limits less than approximately $35 \mathrm{~km} / \mathrm{h}(22 \mathrm{mph})$ and ADT less than approximately 2,500 vehicles are candidates for mixed-traffic conditions according to Danish bikeway design guidance [4].

Implementing shared-use facilities can be an economical solution to a growing need for bikeways. The differing performance capabilities of motor vehicles and bicycles, and the vulnerable nature of cyclists, creates challenges regarding safety and mobility when roadway space is shared, however. There is a growing body of research related to vehicle-bicycle interactions. Many of these studies focus on lateral positioning and passing behavior, but there has been little empirical research concerning the effects bicycles might have on motor vehicle speed or travel time. As cities like Portland experience a mode shift toward bicycling, it is necessary to study the impacts these changes may have on the existing transportation network and motorized vehicles.

One particular concern of some motorists is that unless bicycle lanes are implemented, bicycles will slow down motor vehicles. Motorists may interpret such speed reductions as confining their movement, leading to feelings of stress and the perception of congestion. Although a complex relationship exists between travel time and travel speed in urban areas [5-6], research involving a simulated traffic study has prompted discussions that warn of travel time delays as the bicycle mode share increases if bicycle lanes are not installed [7-8]. Empirical evidence of this claim is lacking, however. Previous work by Schaefer et al. [9] has suggested that the presence of bicycles on low volume, low speed urban roads without bicycle lanes does not meaningfully reduce passenger car speeds at most sites that meet bikeway design guidelines for mixed-traffic roadways. However, this study [9] was limited to six 25 -mph, rather homogeneous sites. Statistically significant differences in mean speed of more than $1 \mathrm{mph}$ were only found at one site where speeds and traffic volumes exceeded those in the bikeway guidance for shared roads, and at another site with a significant grade. These results provided the motivation for a more extensive study utilizing a more diverse set of data collection locations.

This study significantly extends the previous study [9] by incorporating a large number of study sites (40 locations and 75 directional speed datasets) and presenting more diversity with respect to traffic volumes, posted speed limit (PSL), roadway markings, functional classification, and grade. In addition, this study considers the potential effects of oncoming (opposite direction) traffic on motorists' opportunities to overtake a cyclist. The results of this research are more widely applicable and may help guide decisions regarding the implementation of shared bikeways. 


\section{LITERATURE REVIEW}

Shared roads or roads without bicycle lanes may contribute to a substantial portion of an urban bikeway network in some cities. World leaders in bicycling culture, the Danish have developed guidelines for when shared or mixed-traffic roads may be appropriate. The Cycling Embassy of Denmark suggests motor vehicle speeds should be less than $35 \mathrm{~km} / \mathrm{h}(22 \mathrm{mph})$, and traffic volumes should be low (less than approximately 2,500 ADT) for mixed-traffic roadways [4]. Similar guidelines are set forth by the FHWA, indicating shared facilities may be acceptable for urban roads with speeds less than $25 \mathrm{mph}$ and volumes less than 3,000 ADT [10]. The National Association of City Transportation Officials (NACTO) advises a somewhat lower maximum motor vehicle volume of only 1,500 vehicles per day [11], but agrees with the Danish and FHWA range of maximum speeds for shared roads.

As cities continue to encourage bicycling as a primary mode of transportation, the need for additional research regarding the impact of bicycles on traffic operations is highlighted, especially in mixed-traffic contexts. In particular, there appear to be relatively few studies in the traffic literature on the impact of vehicle-bicycle interactions on travel speed or delay.

Most existent studies on vehicle-bicycle interactions have focused on rider position in the roadway, lateral clearance when overtaking, or how these factors may influence safety. For example, research has been conducted on the effects of a cyclist's helmet usage, clothing, and apparent gender on overtaking proximity [12-13]. Other studies have concluded that the presence of shared lane markings (also known as sharrows) encourages cyclists to ride in a more central lane position, which may improve their visibility [14-15].

Lane position also affects the type of interference bicycles may impose on motor vehicles. A cyclist riding to the right of a wide lane may impose little friction interference to a passing motor vehicle, which may not need to reduce travel speed significantly if there is room to overtake safely. When a cyclist occupies a more substantial portion of the lane, at the center or left, block interference is more likely to occur, forcing the motorist to reduce their speed and wait for an opportunity to overtake [16].

When block interference occurs on a two-lane road, and a motorist desires to overtake, they must find an appropriate gap in oncoming (opposite direction) traffic. The decision to initiate a passing maneuver is guided by the required passing sight distance (PSD), which is a function of the speeds and lengths of the bicycle and motor vehicle, the headways between the bicycle and the motor vehicle before and after overtaking, a minimum clearance interval with oncoming traffic, and the overtaking motorist's perception-reaction time [17].

The effects of block interference were demonstrated in a study using empirical data from three urban road sections in Beijing, China [16]. Researchers found that as bicycle lane widths decreased or bicycle volumes increased, block interference was more likely to occur due to bicycles spilling into the motor vehicle lane, offering insufficient width for motor vehicles to pass. When no interference occurred, mean motor vehicle speeds ranged from $35.15 \mathrm{~km} / \mathrm{h}$ to $41.56 \mathrm{~km} / \mathrm{h}(21.84 \mathrm{mph}$ to $25.82 \mathrm{mph})$. Mean speeds were reduced by $17-21 \%$ under friction interference conditions. Under block interference, mean speeds were reduced by $29-37 \%$. The lane widths were stated to be $3.7 \mathrm{~m}(12 \mathrm{ft}$.), but the PSL or the roadway volume was not indicated.

When empirical data is unavailable, simulations have been used to model vehicle-bicycle interactions. Oketch [18] designed a model to simulate heterogeneous traffic behavior on a two-lane road with three-meter (10 ft.) lane widths. Model parameters included an average desired speed of $80 \mathrm{~km} / \mathrm{h}(50$ $\mathrm{mph}$ ) and a flow of 1,000 vehicles per hour to simulate a typical urban arterial road. Compared to a homogeneous traffic stream of private cars, a simulation including $25 \%$ bicycles and $75 \%$ private cars showed a $36 \%$ decrease in capacity. A reduction in the mean free-flow speed was cited as the cause of the decreased capacity. Note, however, that the model parameter values set for speed and traffic volume in this simulation are well outside of the mentioned bicycle design recommendations for mixed-traffic roadways.

Gosse and Clarens [8] also used simulations to quantify the effects of bicycles on travel time for a two-lane urban road. The simulations were based on a motor vehicle speed of $37.4 \mathrm{mph}$ and used different combinations of values for motor vehicle lane widths, grades, and bicycle mode share percentages. The 
researchers concluded travel time delay costs were incurred when the bicycle mode share reached $10 \%$ as a result of a 'stuck vehicle condition,' whereby shared travel lanes did not offer sufficient width for heavy vehicles to pass safely. A positive 4\% grade magnified the effect of the stuck vehicle condition.

Alternatively, when adequate space was provided for larger vehicles to pass, travel time delay costs were reduced with a $10 \%$ bicycle mode share. These simulation studies can be useful, but the parameters used to model the roadway or driver-cyclist interactions do not capture the full spectrum of real-world situations.

\section{DATA COLLECTION}

Traffic speed data collected from 2015 through 2019, obtained from the Portland Bureau of Transportation (PBOT), was used to study the effects of bicycles may have on passenger car speeds on roads without bicycle lanes. PBOT regularly performs traffic data collection throughout the city using pneumatic tubes configured to measure speed and classify vehicles according to a modified FHWA Scheme F [18]. Under the modified classification scheme, bicycles are considered class one vehicles, and passenger cars are considered class two. Pneumatic tubes are commonly used to perform short-term traffic counts. The accuracy of pneumatic tubes to count and record speeds of bicycles was investigated by Nordback et al. [20]. The researchers found that the JAMAR brand tubes performed better than two other brands of classification counters tested and that manually computed bicycle speeds were in agreeance with those reported by the JAMAR model. PBOT has been using these JAMAR brand tube counters for many years, and crews are skilled in the set-up and placement of these tubes to collect data for both motorized vehicles and bicycles. The data collection equipment records individual vehicles with an associated timestamp, accurate to the second, and speed in 1-mph increments. Bidirectional speed data were collected at 40 locations for a minimum of one full day. In some cases, only one direction of traffic was analyzed due to the number of observations required. This resulted in 75 datasets available for analysis.

All sites were located along two-way, two-lane urban roads without bicycle lanes in Portland. Sites were chosen to represent a variety of roadway characteristics. Considerations were made for roadway functional class, centerline marking, ADT, PSL, and grade. Local and urban collector roads were represented (with 39 and 36 datasets, respectively), and class two ADT ranged from fewer than 200 up to approximately 4,700 vehicles per day. Parallel parking was permitted at all locations. Road widths ranged from $34 \mathrm{ft}$. to $40 \mathrm{ft}$.

Dashed yellow center lines were present in 12 datasets, and double yellow center lines were present in two datasets. The remaining 61 datasets did not have a continuous center lane marking, but double yellow lines were present within approximately $40 \mathrm{ft}$. of traffic control devices. Sharrows (shared lane markings) were also present along these streets. These datasets were collected from roadways designated as neighborhood greenways - roads with relatively low motorized traffic volumes and speeds, typically meeting the recommendations for mixed-traffic roads. Traffic calming, such as speed humps and mini traffic circles, are usually present along neighborhood greenways to deter speeding and cut-through traffic. Bicycles often comprise a significantly greater portion of the total traffic than the citywide average on these roads. The mean class one percentage for the 61 neighborhood greenway datasets was $43 \%$, compared to an average of $3 \%$ for the remaining datasets.

Grades were estimated from a ten-foot interval contour map [21] and ranged between $-5 \%$ and $5 \%$. Two of the datasets had a speed limit of $30 \mathrm{mph}, 39$ datasets had a $25-\mathrm{mph}$ speed limit, and 34 datasets had a 20-mph speed limit. Figures $1-\mathbf{3}$ provide representative street views of a neighborhood greenway local road, an urban collector with a dotted yellow centerline, and an urban collector with a double yellow centerline, respectively. 


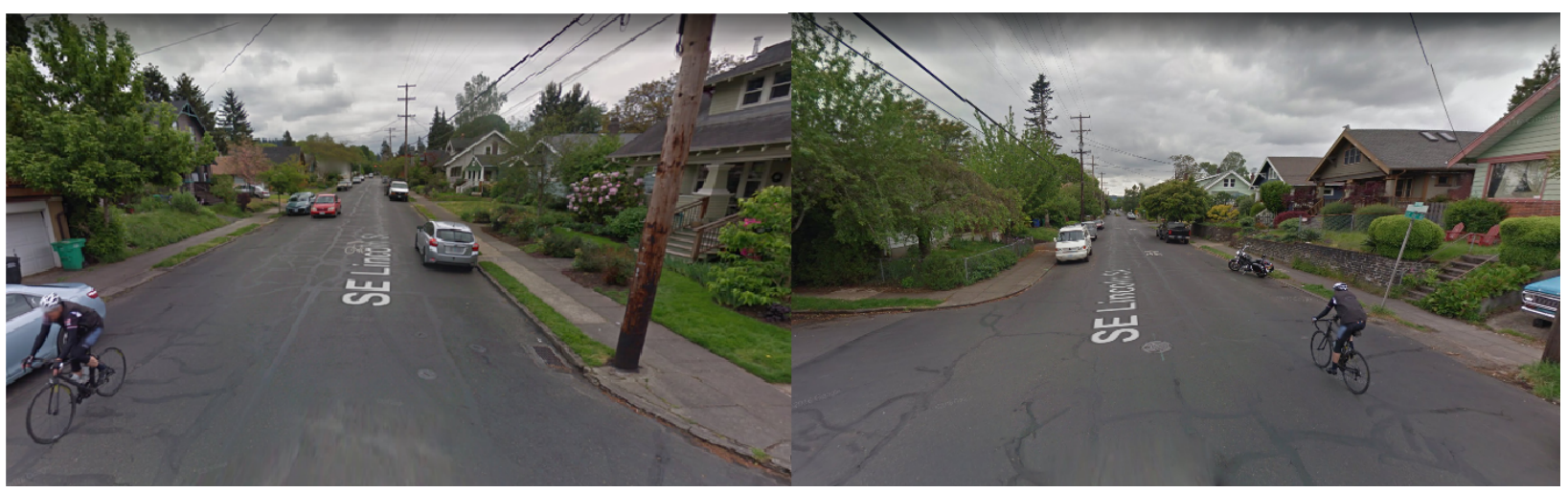

Figure 1 Neighborhood greenway local street without a centerline. SE Lincoln east of $48^{\text {th }}$, eastbound (left) and westbound (right) [22].

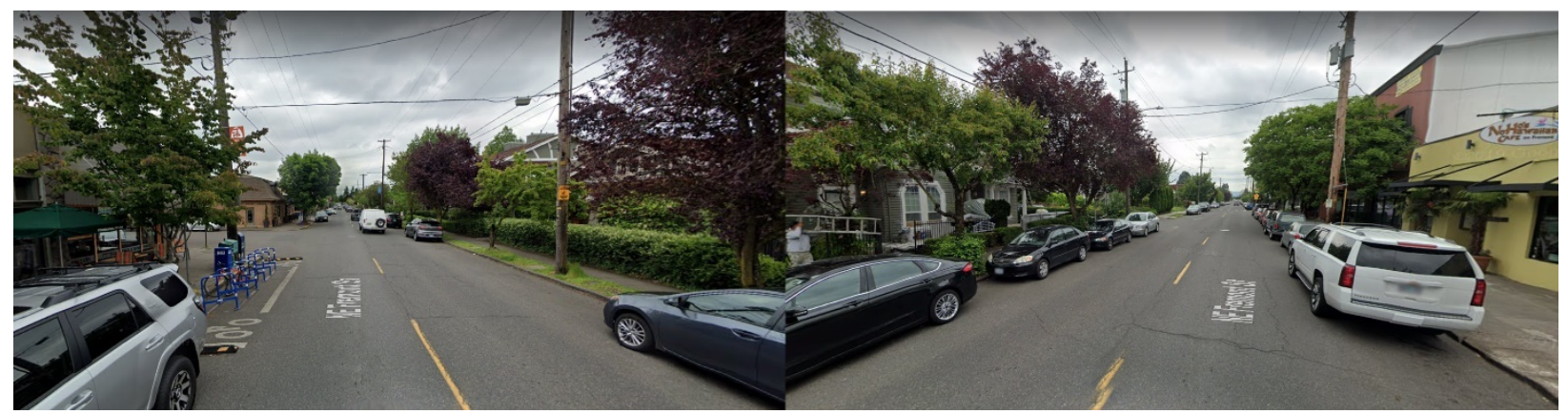

Figure 2 Urban collector with dotted yellow centerline. NE Fremont east of $46^{\text {th }}$, eastbound (left) and westbound (right) [23].

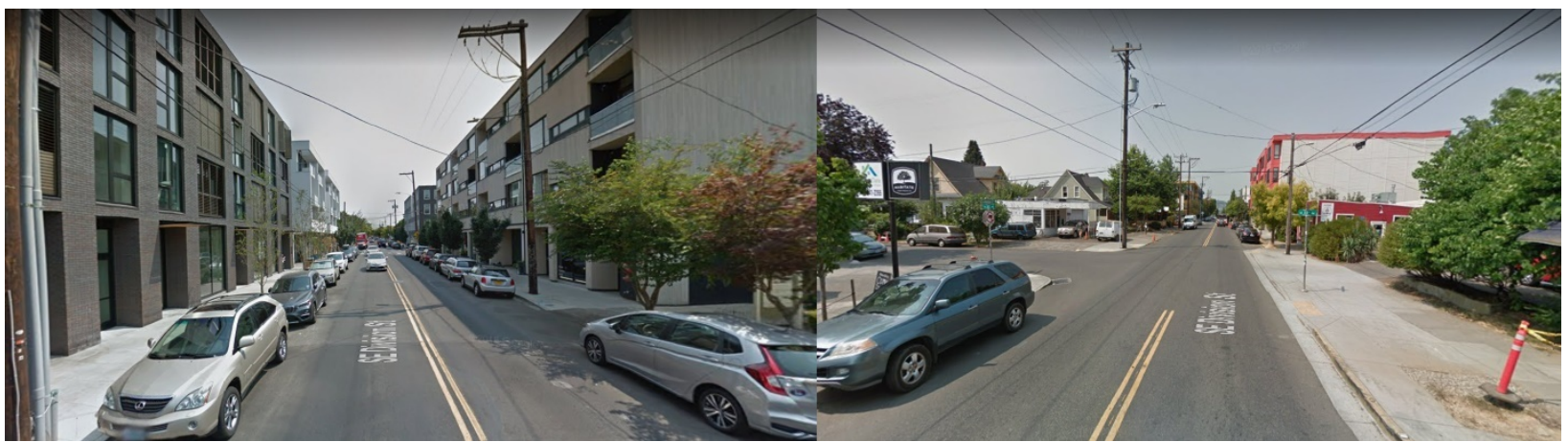

Figure 3 Urban collector with double yellow centerline. SE Division east of $33^{\text {rd }}$, eastbound (left) and westbound (right) [24].

Pneumatic tubes for data collection count axles and cannot directly differentiate between motorized class one vehicles such as motorcycles or e-bikes and pedal bicycles. Motorcycles make up a small percentage of traffic and account for less than $1 \%$ of vehicle miles traveled [25-26], and e-bikes still comprise a small fraction of bicycle sales in the U.S. [27-28]. Nonetheless, to prevent artificial inflation of bicycle speeds, histograms were utilized to filter out class one observations with speeds higher than would typically be expected of a pedal cyclist. Studies in the U.S. have reported average bicycle speeds ranging between $11 \mathrm{mph}$ and $15.5 \mathrm{mph}$. Faster speeds were observed when traveling in bicycle lanes than on off-street paths [29-30]. It is also possible for more advanced cyclists and those riding on a downhill 
grade to reach speeds up to $30 \mathrm{mph}$ [31]. The class one speed histograms were examined in conjunction with the estimated road grade to ensure only observations with speeds reasonable of pedal cyclists were included. A typical example of a class one speed distribution presenting two modes, corresponding to lower speed bicycles and higher speed motorized class one vehicles is shown on the left of Figure 4. Note that the mode on the right side of this histogram coincides with this location's PSL of $30 \mathrm{mph}$. After the data cleaning, the mean class one speed was approximately equal to $15 \mathrm{mph}$. The histogram on the right in Figure 4 is from a location with a $25-\mathrm{mph}$ PSL, at which class one traffic is dominated by bicycles. The mean class one speed for this dataset was approximately $16 \mathrm{mph}$ - slightly higher than the typical range due to a $1 \%$ downhill grade.
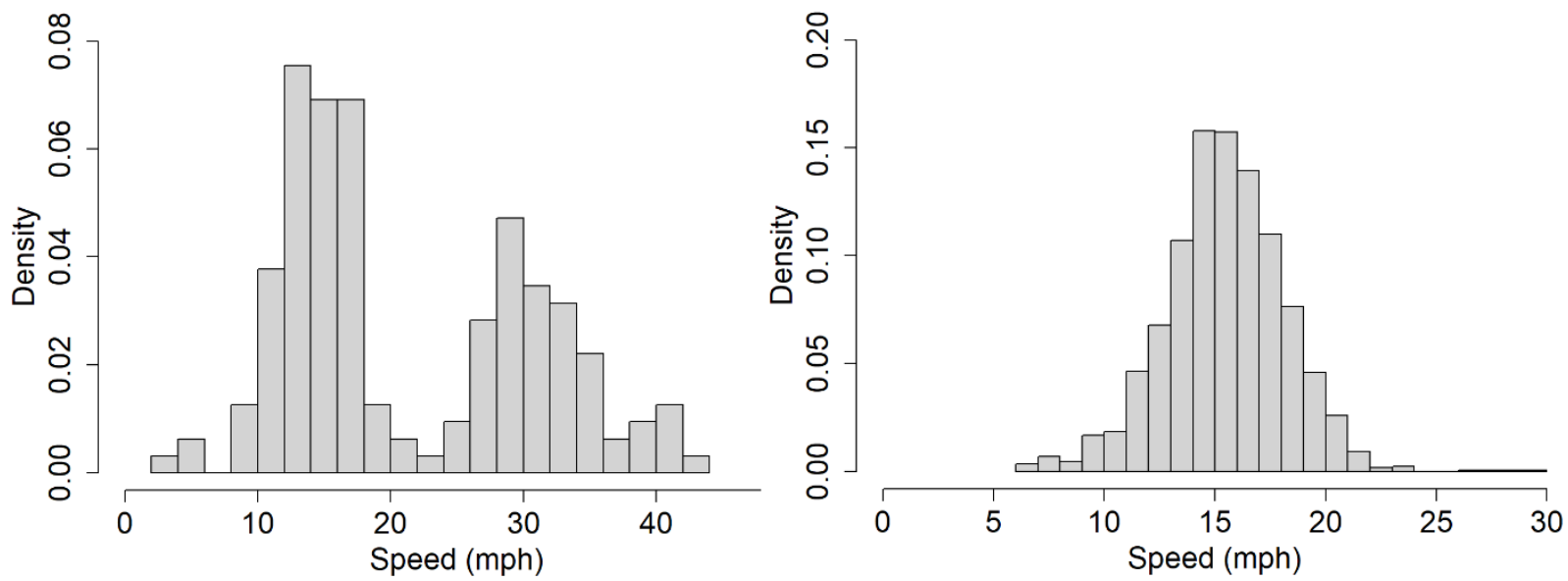

Figure 4 Bimodal class one speed distribution indicating the presence of bicycles and motorized class one vehicles (left), and class one speed histogram from a location where bicycles are the dominant class one vehicle type (right).

\section{ANALYSIS}

Upon encountering a slower-moving bicycle from the rear, a motorist may be forced to reduce their speed until an opportunity to overtake presents itself. If roadway or traffic conditions do not provide sufficient opportunities for overtaking, delay may occur, and additional motor vehicles may begin to queue behind the cyclist. Based on this premise, observations of passenger cars (class two vehicles) belonging to one of two scenarios were selected from the data. The two scenarios are described as follows: in scenario (i), a passenger car was preceded by a bicycle (class one vehicle), and in scenario (ii), a passenger car was preceded by another passenger car. These data selections enable testing of the hypothesis that bicycles cause reduced passenger car speeds on roads without bicycle lanes due to friction or block interference.

The mean speeds of scenario (i) and scenario (ii) vehicles were compared using a two-sample $t$ test. The null hypothesis states that the difference between the mean speeds of scenario (ii) and scenario (i) is equal to $1 \mathrm{mph}, \mathrm{H}_{0}: \mu_{\mathrm{ii}}-\mu_{\mathrm{i}}=1$. The alternative hypothesis states that the mean speed of scenario (i) is less than the mean speed of scenario (ii) by more than $1 \mathrm{mph}, \mathrm{H}_{\mathrm{A}}: \mu_{\mathrm{ii}}-\mu_{\mathrm{i}}>1$. Note that a difference of $1 \mathrm{mph}$ was chosen to match the sensitivity of the data collection equipment, which records speeds in integer values, and also to use a metric that provide results that are "practically significant" instead of just "statistically significant" because a 1-mph difference is unlikely to be noticed by drivers. For $p<0.05$, the null hypothesis is rejected. If $p \geq 0.05$, the sample data fail to reject the null hypothesis.

The $85^{\text {th }}$ percentile speed is frequently used as a performance metric and a baseline for determining appropriate speed limits [32]. For this reason, a modified $t$-test was performed with the $85^{\text {th }}$ percentile speeds of scenario (i) and scenario (ii) vehicles. Details of the test can be found in Hou et al. [33]. Similar to the hypothesis test of mean speeds, this null hypothesis states that the difference between the $85^{\text {th }}$ percentile speeds of scenario (ii) and scenario (i) is equal to $1 \mathrm{mph}, \mathrm{H}_{0}: \zeta_{85}$, ii $-\zeta_{85, \mathrm{i}}=1$. The 
alternative hypothesis states that the $85^{\text {th }}$ percentile speed of scenario (i) is less than the $85^{\text {th }}$ percentile speed of scenario (ii) by more than $1 \mathrm{mph}, \mathrm{H}_{\mathrm{A}}: \zeta_{85, \mathrm{ii}}-\zeta_{85, \mathrm{i}}>1$. Again, for $p<0.05$, the null hypothesis is rejected.

The availability of bidirectional data allowed for an investigation of how gaps in oncoming traffic may impact scenario (i) speeds. Henceforward, an "oncoming" vehicle travels in a direction that opposes the direction of travel of the bicycle. Under the assumption that a scenario (i) vehicle must occupy a portion of the oncoming lane to overtake a bicycle, opportunities for passing are dependent on the required passing sight distance (PSD), and subsequently, gaps with oncoming traffic. PSD can be calculated as the sum of four distances, described as follows:

- the distance the passing vehicle travels during a one-second perception-reaction time,

- the distance traveled by the passing vehicle while occupying the oncoming (opposite direction of travel) lane,

- the clearance distance between the passing and oncoming vehicle that creates a one-second gap, and,

- the distance traveled by the oncoming vehicle during two-thirds of the time the passing vehicle occupies the oncoming lane [17].

The required PSD can be used to calculate the gap time with an oncoming vehicle that is necessary to overtake safely - the safe passing gap. In this analysis, the safe passing gap was calculated assuming an overtaking vehicle length of $19 \mathrm{ft}$., a bicycle length of $6 \mathrm{ft}$., a one second gap between the overtaking vehicle and the bicycle before and after the maneuver, and an oncoming vehicle speed equal to the PSL. If the existent gap time between a scenario (i) vehicle that wishes to overtake and an oncoming vehicle is less than the safe passing gap, it is expected that a lower scenario (i) vehicle speed would result.

To determine if the presence of an oncoming vehicle may have suppressed a scenario (i) vehicle from initiating an overtaking maneuver, observations of oncoming vehicles arriving at the pneumatic tubes directly before and directly after a scenario (i) vehicle were extracted from the data. This data selection follows from the possibility of an oncoming vehicle that was suppressing a scenario (i) vehicle from overtaking to arrive at the tubes just before or after the scenario (i) vehicle. Bicycle observations were excluded from the oncoming data since they may not occupy the full width of the lane, thereby enabling an overtaking maneuver despite the presence of the oncoming vehicle. The observed gap times between the selected oncoming vehicles and the scenario (i) vehicle were calculated from the timestamps of the observations and compared to the safe passing gap.

The $t$-tests described above were first performed on all scenario (i) and scenario (ii) observations to provide an average baseline of expected speed changes throughout all hours of the day. The $t$-tests were then performed on three subsets of the data, and results were compared to the baseline conditions. The first subset of data included all scenario (ii) observations and retained only scenario (i) observations in which the existent gap times with the selected oncoming vehicles were greater than or equal to the safe passing gap. An existent gap with the selected oncoming vehicles greater than or equal to the safe passing gap would indicate that the scenario (i) vehicle was able to overtake the bicycle if so desired. The second subset of data included all scenario (ii) observations and only scenario (i) observations in which the existent gap times with the selected oncoming vehicles were less than the safe passing gap - suggesting the suppression of overtaking maneuvers. The third subset of data was limited to scenario (i) and scenario (ii) observations in which the gap times between the leading and following vehicles of the respective scenario (the bicycle and passenger car for scenario (i), e.g.) was less than ten seconds, representing conditions of more constrained flow. Scenario (i) and (ii) data subsets were excluded from the hypothesis testing if they contained fewer than 20 observations.

\section{RESULTS}

Of the 75 datasets analyzed using all observations, only six (8\%) were found to reject the null hypothesis stating that the mean speeds of scenarios (i) and (ii) were equal. Rejection of the null indicates that the mean speed of scenario (i) was more than $1 \mathrm{mph}$ slower than the mean speed of scenario (ii) in 
these datasets. All six datasets were collected from urban collector roads. Table 1 provides details of the hypothesis test results for the six datasets that presented significant differences in mean speeds of more than $1 \mathrm{mph}$. The PSL, class one and class two ADT, class one mean speed, grade, and type of road marking at these sites are also given in Table 1. Scenario (ii) mean speeds ranged from 1.6 to $3.3 \mathrm{mph}$ higher than scenario (i) mean speeds.

When including all observations, only one of the 75 datasets, collected at eastbound Fremont west of 43rd in July 2019, was found to have a significant decrease in $85^{\text {th }}$ percentile speeds of more than 1 mph for scenario (i) when compared to scenario (ii) $(p=0.01)$. Note that the $85^{\text {th }}$ percentile speeds for scenario (i) and scenario (ii) were higher than the $20 \mathrm{mph}$ PSL, at $23 \mathrm{mph}$ and $26 \mathrm{mph}$, respectively. This dataset also displayed mean speeds for scenario (i) that were approximately three miles per hour slower than for scenario (ii) $(p=0.0)$.

TABLE 1 Hypothesis test results for the six datasets using all observations that reject the null hypothesis of equal mean speeds.

\begin{tabular}{|c|c|c|c|c|c|c|c|c|c|}
\hline \multirow[b]{2}{*}{ Dataset } & \multirow[b]{2}{*}{ PSL } & \multicolumn{2}{|c|}{ ADT } & \multicolumn{3}{|c|}{ Mean } & \multirow[b]{2}{*}{$\begin{array}{c}p \text { - } \\
\text { value }\end{array}$} & \multirow[b]{2}{*}{$\begin{array}{c}\text { Grade } \\
\%\end{array}$} & \multirow[b]{2}{*}{$\begin{array}{c}\text { Road } \\
\text { Marking }\end{array}$} \\
\hline & & $\begin{array}{c}\text { Class } \\
1\end{array}$ & $\begin{array}{c}\text { Class } \\
2\end{array}$ & $\begin{array}{c}\text { Class } \\
1\end{array}$ & (i) & (ii) & & & \\
\hline $\begin{array}{l}\text { Alberta E of 11th Sep } \\
2016 \text { WB }\end{array}$ & 25 & 132 & 2949 & 14.54 & 22.89 & 25.01 & 0.039 & -0.4 & $\begin{array}{l}\text { Dotted } \\
\text { Yellow }\end{array}$ \\
\hline $\begin{array}{l}\text { Clinton W of 14th Sep } \\
2019 \text { WB }\end{array}$ & 20 & 933 & 428 & 14.52 & 20.04 & 21.62 & 0.027 & -0.7 & Sharrow \\
\hline $\begin{array}{l}\text { Division E of 23rd Jul } \\
2015 \text { WB }\end{array}$ & 25 & 124 & 4462 & 18.13 & 23.95 & 26.26 & 0.017 & -4.1 & $\begin{array}{l}\text { Double } \\
\text { Yellow }\end{array}$ \\
\hline $\begin{array}{l}\text { Fremont W of 43rd } \\
\text { Jul } 2019 \mathrm{~EB}^{*}\end{array}$ & 20 & 187 & 4689 & 9.42 & 17.65 & 20.97 & 0.000 & 0.0 & $\begin{array}{l}\text { Dotted } \\
\text { Yellow }\end{array}$ \\
\hline $\begin{array}{l}\text { Willamette E of } \\
\text { Mohawk Jul } 2019 \text { EB }\end{array}$ & 30 & 88 & 2958 & 14.93 & 27.50 & 30.12 & 0.030 & 0.8 & $\begin{array}{l}\text { Dotted } \\
\text { Yellow }\end{array}$ \\
\hline $\begin{array}{l}\text { Willamette E of } \\
\text { Mohawk Jul } 2019 \text { WB }\end{array}$ & 30 & 115 & 2937 & 16.26 & 27.22 & 29.77 & 0.005 & -0.8 & $\begin{array}{l}\text { Dotted } \\
\text { Yellow }\end{array}$ \\
\hline
\end{tabular}

*A significant decrease of more than $1 \mathrm{mph}$ in the $85^{\text {th }}$ percentile speed was also observed in this dataset.

The results of $t$-test for the mean speed on the first subset of data, in which the scenario (i) vehicle had an opportunity to overtake the bicycle (when observed time gaps between the scenario (i) and the selected oncoming vehicles were greater than or equal to the safe passing gap), indicate that significant speed reductions of more than $1 \mathrm{mph}(p<0.05)$ were present in only four of the 75 datasets tested $(5.3 \%)$. The $t$-test results on this data subset for the $85^{\text {th }}$ percentile speeds revealed one dataset in which a significant speed reduction occurred.

Within the second subset of data, in which the scenario (i) vehicle did not have a sufficient gap time with the selected oncoming vehicles to safely pass the bicycle, significant reductions in the mean speed of more than $1 \mathrm{mph}$ were observed in six of the 60 datasets tested (10\%). Six of the datasets also displayed significantly reduced $85^{\text {th }}$ percentile speeds.

The third subset of data, including observations with gap times of less than ten seconds between the lead and following vehicle in the respective vehicle scenarios, showed a higher proportion of the datasets tested had significantly reduced mean speeds of more than $1 \mathrm{mph}$ as compared to the full datasets and the previous two subsets. A total of 24 out of 63 datasets tested (38\%) rejected the null hypothesis for the mean speed $t$-test. Meanwhile, seven of these 63 datasets $(11 \%)$ indicated a significant reduction of the $85^{\text {th }}$ percentile speeds occurred.

The percentages of datasets suggesting significant speed reductions in the mean or $85^{\text {th }}$ percentile speeds for all observations and the three subsets can be visualized in Figure 5 and Figure 6. The results in these figures have been further categorized to show the percentages according to the functional class 
(Figure 5) and the neighborhood greenway status (Figure 6). Recall that the neighborhood greenways did not have continuous centerlines, but dashed or double yellow centerlines were present on the nonneighborhood greenways. Thus, the neighborhood greenway categories also represent the presence of centerline categories. It should also be noted that all local roads in this study were also neighborhood greenways, but not all neighborhood greenways were local roads.

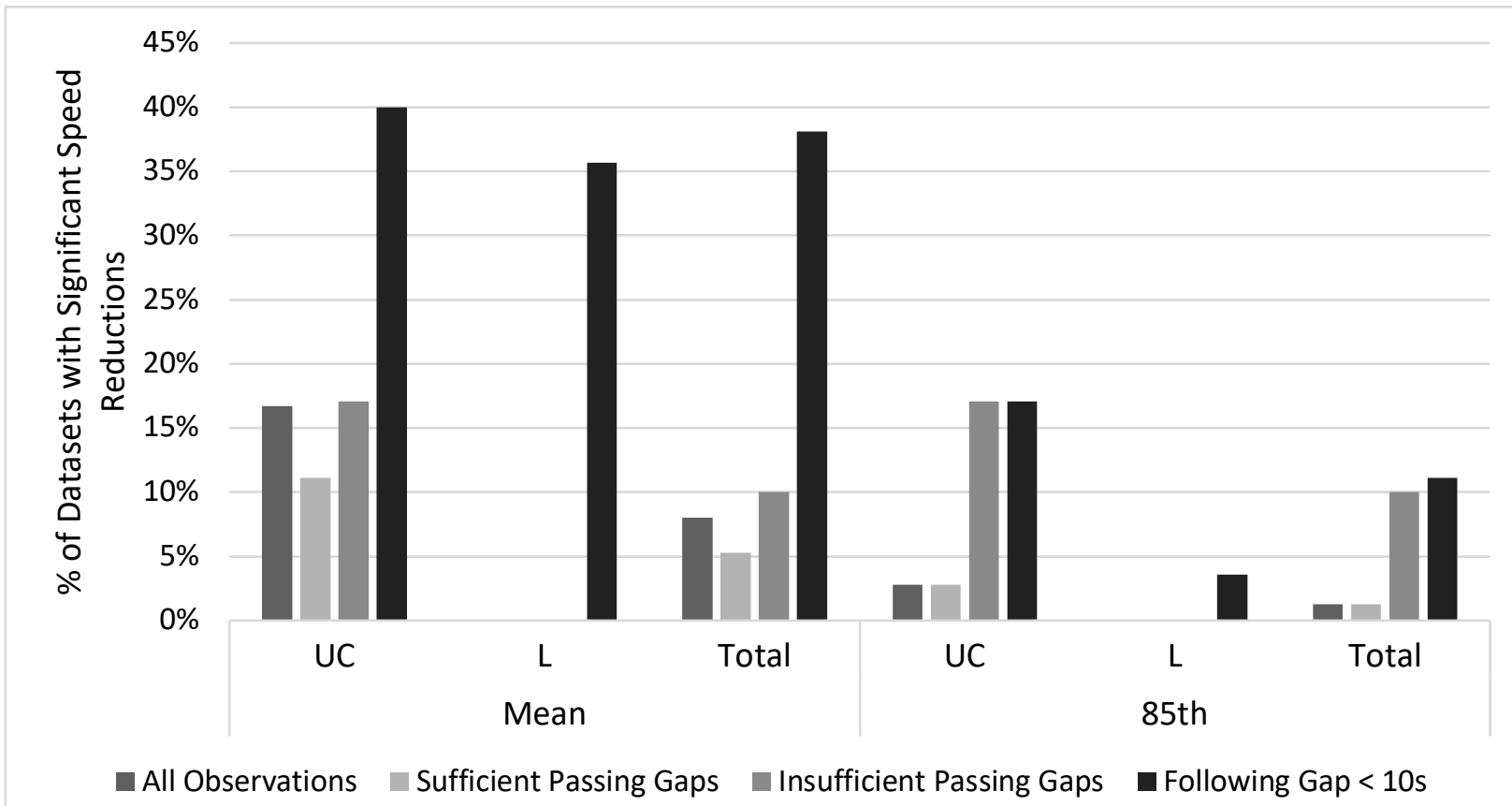

Figure 5 Percentage of datasets tested indicating significant speed reductions for all observations and three subsets, according to functional classification $(\mathrm{L}=$ local, $\mathrm{UC}=$ urban collector).

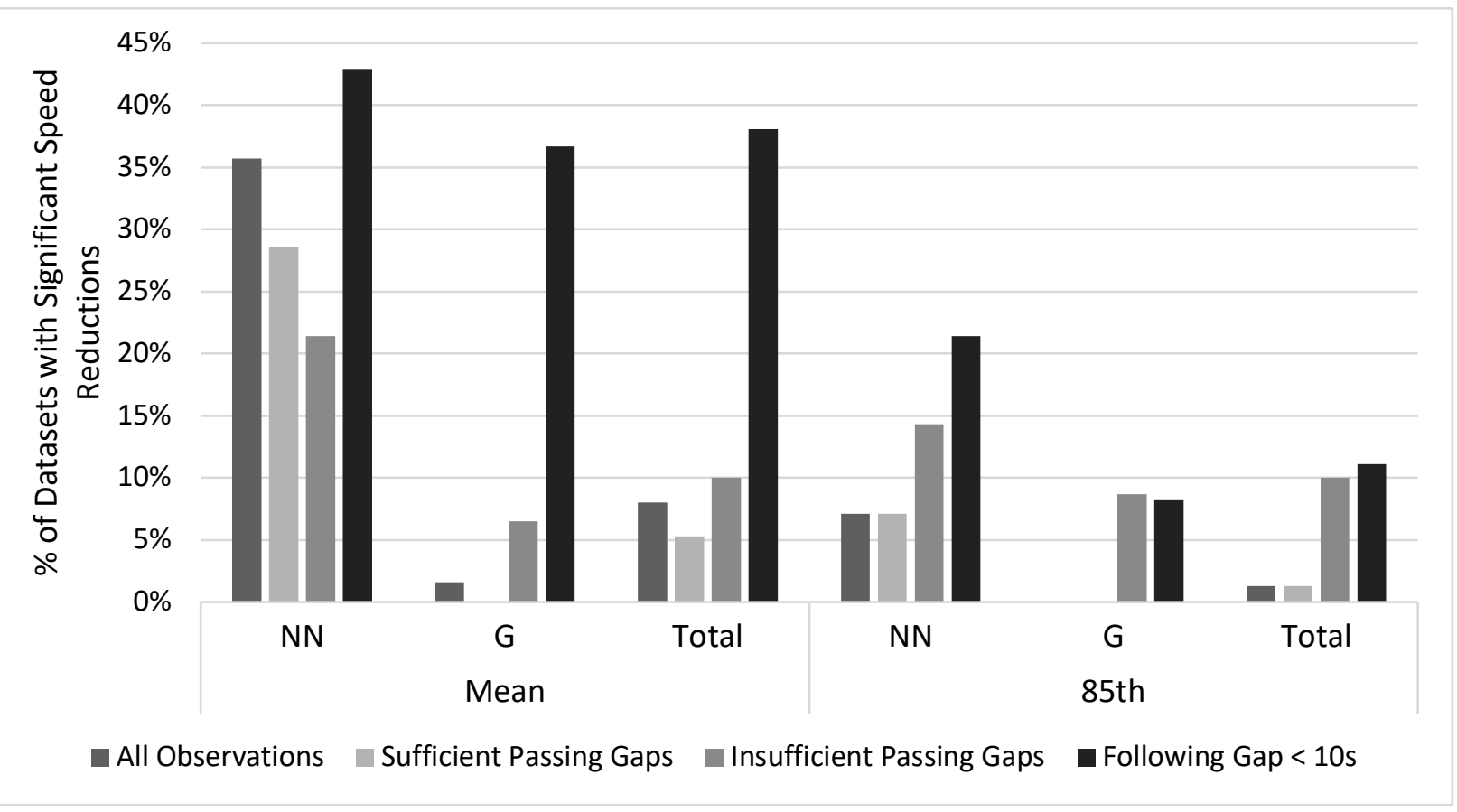


Figure 6 Percentage of datasets tested indicating significant speed reductions for all observations and three subsets, according to neighborhood greenway status $(\mathrm{G}=$ neighborhood greenway, $\mathrm{NN}=$ non-neighborhood greenway).

The results shown in Figure 5 and Figure 6 suggest that for most categories, mean and $85^{\text {th }}$ percetile speeds were less likely to be reduced by more than $1 \mathrm{mph}$ when the observed gap times between the scenario (i) and selected oncoming vehicles were sufficient for passing the bicycle (i.e., greater than or equal to the safe passing gap) compared to when the gap times with the oncoming vehicles were insufficient for passing (less than the safe passing gap). The non-neighborhood category (where centerlines are present) displays an exception to this pattern when considering mean speeds (Figure 6). A higher percentage of datasets indicated significantly reduced mean speeds occurred when gaps with oncoming vehicles were greater than or equal to the safe passing gap (29\%) compared to when the gaps with oncoming vehicles were less than the safe passing gap (21\%). Smaller gap times between the leading and following vehicles of the respective scenarios, representing more constrained flow conditions, also appear to increase the likelihood of significantly reduced mean or $85^{\text {th }}$ percentile scenario (i) speeds.

In addition to these observations regarding the three data subsets, differences were found within the functional class and neighborhood greenway status categories. A higher percentage of nonneighborhood or urban collector datasets displayed significantly reduced speeds, compared to neighborhood greenways or local roads for all subsets of data.

\section{DISCUSSION}

Based on the results of the $t$-tests comparing the speeds of passenger cars following bicycles (scenario (i)) and passenger cars following other passenger cars (scenario (ii)), there is little evidence to suggest that bicycles lead to a practical reduction $(>1 \mathrm{mph}$ ) in passenger car speeds on low volume, low speed urban roads without bicycle lanes under general operating conditions.

In traffic literature, free-flow speeds are defined as those occurring when a vehicle is traveling uninhibited by the preceding vehicle. A gap time between vehicles greater than four to six seconds is typically used as a threshold to identify vehicles in free-flow conditions. When motorized vehicles are forced to follow a slower-moving bicycle under inhibited flow conditions, it is expected that mean and $85^{\text {th }}$ percentile speeds will be reduced. This is demonstrated by the results of the $t$-tests on datasets limited to observations with gap times of less than ten seconds between the leading and following vehicles of the respective scenarios. Within this data subset, a somewhat higher percentage of significantly reduced mean or $85^{\text {th }}$ percentile speeds were observed than when all observations were tested.

When overtaking opportunities are sufficiently abundant, a passenger car approaching a bicycle from behind may not need to significantly reduce their speed for a meaningful amount of time. Thus, the overall speed of traffic would be largely unaffected. This outcome is evidenced by the results of the $t$-tests performed when scenario (i) data were subset according to the potential for an opportunity to overtake the bicycle. When the gap times between the scenario (i) and the selected oncoming vehicles were greater than or equal to the safe passing gap, a lower percentage of datasets showed evidence that scenario (i) mean or $85^{\text {th }}$ percentile speeds were reduced by more than $1 \mathrm{mph}$, compared to when the gap times with oncoming vehicles were less than the safe passing gap.

Overall, the $t$-test results produced limited evidence that passenger car speeds are reduced on these lower volume, low speed, urban roads without bike lanes. Mean or $85^{\text {th }}$ percentile speed reductions of more than $1 \mathrm{mph}$ appear to occur less frequently on local functionally classed roads and neighborhood greenways, which prioritize active travelers and typically have high bicycle volumes. The unique characteristics of the neighborhood greenways may play an additional role in speed behavior by communicating to motorists and setting the expectation of encountering a cyclist, leading to lower overall motorized speeds.

When all observations were considered, only six of the 75 datasets analyzed (8\%) indicated that scenario (i) mean speeds were significantly lower than scenario (ii) by more than $1 \mathrm{mph}$. Differences in mean speeds for scenario (i) and scenario (ii) in these datasets ranged from 1.6 to $3.3 \mathrm{mph}$. Only one of 
these datasets demonstrated a significant difference in $85^{\text {th }}$ percentile speeds when all observations were analyzed. A few common characteristics were present in these datasets that may have contributed to the difference in speeds. All six datasets were collected from urban collector roads, and the $85^{\text {th }}$ percentile speeds for both vehicle scenarios were all in excess of the PSL. Additionally, a high percentage (38\% to $58 \%$ ) of class two vehicles exceeding the PSL was observed within these datasets. Grade did not appear to be a significant factor, however. At five of the sites, the presence of centerlines and class two ADT greater than is recommended by Danish bikeway design guidance for shared roads may have influenced motorists' decision to overtake. Larger speed differentials were observed between bicycles and passenger cars in two datasets, likely causing motorists to decrease speed when overtaking on account of safety. The PSL at these two sites also exceeded the recommendations of the bikeway design guidance, and the decreased scenario (i) speeds provide additional evidence of the design guidance applicability. One site, westbound Clinton west of $14^{\text {th }}$, differed somewhat from the other five sites. At this location, a centerline is absent, and priority is given to bicycles, which comprise nearly $63 \%$ of the total traffic. The class two ADT and PSL for this dataset were within the acceptable range for shared roads. Speed humps are present throughout this segment of the roadway at roughly 400-500 ft. intervals to calm traffic. Motorists may choose to delay overtaking a bicycle due to the presence of a downstream speed hump and the nature of braking and accelerating associated with it. A traffic signal is also present at a T-intersection approximately $425 \mathrm{ft}$. downstream of the data collection location. This distance was insufficient for overtaking according to the calculated PSD for $67 \%$ of the scenario (i) observations, likely forcing motorists to delay overtaking until the intersection was cleared.

The hypothesis tests were not conducted separately for peak hours due to the typically low volumes throughout all hours of the day at most sites. However, peak hours had previously been calculated as the eight consecutive 15-minute intervals (two hours in total) with the highest passenger car counts. Peak hours for same-direction and opposing-direction traffic were found to overlap in just 16 of the 75 datasets. Due to the directionality that was generally present with the peak-hour traffic, likely allowing larger oncoming gaps and more opportunities for overtaking, it is possible that little to no additional impact on speeds would be observed during a peak-hour analysis. This conjecture, as well as the possible effects of vehicle platooning or traffic signal progression, could be further investigated in future research.

\section{CONCLUSIONS}

This research has provided a detailed comparative analysis of passenger car speeds using two vehicle scenarios: (i) a passenger car that was preceded by a bicycle, and (ii) a passenger car that was preceded by another passenger car. This research addressed the limitations of a previous study [9] by incorporating a significant number of study sites displaying a wide variety of characteristics with respect to functional class, grade, traffic volume and composition, and PSL. As the bicycle mode share continues to grow, it will be increasingly important to design and maintain robust networks of bicycle facilities, and these results indicate that shared roads can contribute substantially to those networks while preserving the travel speed of motorized vehicles.

The mean and $85^{\text {th }}$ percentile speeds of the two vehicle following scenarios were compared using $t$-tests. These $t$-tests were performed on all observations and three subsets of the data to investigate the effects of overtaking opportuities within oncoming traffic and inhibited flow conditions. The results of the analyses presented within this paper predominantly indicate that bicycles are unlikely to lead to reduced passenger car speeds on urban roads without bicycle lanes that meet the design guidelines for shared roadways.

When all observations were considered, a small percentage of datasets did show evidence of significantly different mean speeds, but a significant difference in $85^{\text {th }}$ percentile speeds was only observed in one of the 75 datasets. Overall, the results of the hypothesis testing suggest that scenario (i) speeds are less likely to be reduced by more than $1 \mathrm{mph}$ on streets that are designated as neighborhood greenways or those that carry a local functional classification. 
Even if speed reductions are statistically significant, this does not necessarily imply that these reduced speeds have a meaningful impact in terms of travel time. The relationship between travel time and speed is relatively complex, and road users in urban areas generally overestimate the actual time savings associated with higher travel speeds [5-6]. Traffic signals and stop signs are more likely to increase motorists' travel time in streets that meet the guidelines for mixed-traffic roadways. Future studies, like [34], that account for each vehicle's travel time between successive data collection locations, can provide additional information about the main sources of delay in low speed, low volume urban roads with a high percentage of active travelers.

\section{ACKNOWLEDGMENTS}

The authors would like to acknowledge Tom Jensen and Scott Batson of PBOT for providing the data used in this analysis.

\section{AUTHOR CONTRIBUTIONS}

The authors confirm contribution to the paper as follows: study conception and design: MAF; data collection: PBOT; analysis and interpretation of results: JSS, MAF, AU; draft manuscript preparation: JSS, MAF, AU. All authors reviewed the results and approved the final version of the manuscript. 


\section{REFERENCES}

1. United States Census Bureau. American FactFinder - COMMUTING CHARACTERISTICS BY SEX, 2018 American Community Survey 1-Year Estimates [Internet]. Washington DC: US Census Bureau; 2018 [cited 2020 Jun 21]. Available from: https://data.census.gov/cedsci/table?q=S08\&d=ACS\%201Year\%20Estimates\%20Subject\%20Tables\&tid=ACSST1Y2018.S0801\&vintage $=2018$

2. City of Portland Oregon. Bicycles in Portland Fact Sheet [Internet]. Portland, OR: City of Portland; 2019 [updated 2019 Apr; cited 2020 Jun 21]. Available from: https://www.portlandoregon.gov/transportation/article/407660

3. City of Portland Oregon. Portland Bicycle Plan for 2030 [pdf] [Internet]. Portland, OR: City of Portland; 2010 Feb 11 [cited 2020 Jun 25]. Available from: https://www.portlandoregon.gov/transportation/article/289122

4. Andersen T, Bredal F, Weinreich M, Jensen N, Riisgaard-Dam M, Nielsen MK. Collection of cycle concepts 2012. $2^{\text {nd }}$ ed. Denmark: Cycling Embassy of Denmark; 2012. Planning the cycling infrastructure; p. 53-54.

5. European Conference of Ministers of Transport, OECD/ECMT Transport Research Centre. Speed management. OECD Publishing; 2006.

6. Archer J, Fotheringham N, Symmons M, Corben B. The impact of lowered speed limits in urban/metropolitan areas. (Report No. 276). Clayton, Australia: Monash University Accident Research Centre. 2008 Jan.

7. Andersen, M. Real Talk: Bikes don't reduce congestion without bike lanes [Internet]. Boulder, CO: PeopleForBikes; 2015 Apr 22 [cited 2020 Jun 25]. Available from: https://peopleforbikes.org/blog/real-talk-bikes-cant-reduce-congestion-without-bike-lanes/

8. Gosse C, Clarens A. Quantifying the total cost of infrastructure to enable environmentally preferable decisions: the case of urban roadway design. Environmental Research Letters. 2013 Mar; 8(1):1-9.

9. Schaefer JS, Figliozzi MA, Unnikrishnan A. Evidence from Urban Roads without Bicycle Lanes on the Impact of Bicycle Traffic on Passenger Car Travel Speeds. Transportation Research Record. 2020 Jun 12:0361198120920880.

10. Schultheiss B, Goodman D, Blackburn L, Wood A, Reed D, Elbech M. Bikeway selection guide. United States: Federal Highway Administration Office of Safety; 2019 Feb 1. Report No.: FHWA-SA-18-077. Washington DC: FHWA, p. 23.

11. National Association of City Transportation Officials. Urban bikeway design guide. $2^{\text {nd }}$ ed. Washington DC: Island Press; 2014 Mar 24.

12. Walker I. Drivers overtaking bicyclists: Objective data on the effects of riding position, helmet use, vehicle type and apparent gender. Accident Analysis \& Prevention. 2007 Mar 1;39(2):41725. 
13. Walker I, Garrard I, Jowitt F. The influence of a bicycle commuter's appearance on drivers' overtaking proximities: an on-road test of bicyclist stereotypes, high-visibility clothing and safety aids in the United Kingdom. Accident Analysis \& Prevention. 2014 Mar 1;64:69-77.

14. Brady J, Loskorn J, Mills A, Duthie J, Machemehl R, Beaudet A, Barrea N, Wilkes N, Fialkoff J. Effects of Shared Lane Markings on Bicyclist and Motorist Behavior along Multi-Lane Facilities. Center for Transportation Research, U. of Texas at Austin, Austin, TX. 2010.

15. LaMondia J, Duthie J. Analysis of factors influencing bicycle-vehicle interactions on urban roadways by ordered probit regression. Transportation Research Record. 2012;2314(1):81-88.

16. Jia S, Peng H, Guo J, Chen H. Quantitative analysis of impact of bicycles on vehicles in urban mixed traffic. Journal of Transportation Systems Engineering and Information Technology. 2008 Apr 1;8(2):58-63.

17. Harwood DW, Sun C. Passing sight distance criteria. Transportation Research Board; 2008.

18. Oketch TC. Modeled performance characteristics of heterogeneous traffic streams containing non-motorized vehicles. Transportation Research Board 82nd Annual Meeting [CD-ROM]. 2003.

19. Federal Highway Administration. Traffic monitoring guide. Washington DC: US Department of Transportation; 2016. p. C-1.

20. Nordback K, Kothuri S, Phillips T, Gorecki C, Figliozzi M. Accuracy of bicycle counting with pneumatic tubes in Oregon. Transportation Research Record. 2016;2593(1):8-17.

21. United States Geological Survey. 10 foot contours of the Portland, OR metro area [Internet]. 2011 Jan 24 [modified 2011 May 15; cited 2020 Jun 25]. Available from: https://databasin.org/datasets/e5f48e27860046c6b4bc14d64adf1ceb

22. Google Maps. Google Street View, 4749 SE Lincoln St. [Image on internet]. United States: Google; 2016 Apr [cited 2020 Jul 18]. Available from: https://goo.gl/maps/NxH3nCjBT3C4uwEG7

23. Google Maps. Google Street View, 4624 NE Fremont St. [Image on internet]. United States: Google; 2019 May [cited 2020 Jul 18]. Available from: https:/goo.gl/maps/gmsZy5xw6i2WT6426

24. Google Maps. Google Street View, 3302 SE Division St. [Image on internet]. United States: Google; 2018 Aug [cited 2020 Jul 18]. Available from: https://goo.gl/maps/4Qfv7VLfMo5L9t3T7

25. Hallenbeck M, Rice M, Smith BL, Cornell-Martinez C, Wilkinson J. Vehicle volume distributions by classification; FHWA-PL-97-025 Technical Report.1997 Jul. p. 29.

26. National Highway Traffic Safety Administration. Traffic Safety Facts [pdf] [Internet]. Washington DC: US Department of Transportation; 2013 [cited 2020 Jun 25]. Available from: https://crashstats.nhtsa.dot.gov/Api/Public/ViewPublication/812148\#: :text=Motorcycles\%20ma ma\%20up\%203\%20percent,of\%20all\%20vehicle\%20miles\%20traveled. 
27. McFarland M. Electric bicycles emerge as a hot trend in the U.S. [Internet]. CNNMoney. 2018 [cited 2020 Jun 27]. Available from: https://money.cnn.com/2018/01/17/technology/ebikeselectric-bikes/index.html

28. Wagner I. U.S. Bicycle Industry - Statistics \& Facts [Internet]. Statista. 2019 [cited 2020 June 27]. Available from: https://www.statista.com/topics/1448/bicycle-industry-in-the-us/

29. Miller RE. Width requirements for bikeways: A level of service approach. University of California, Davis; 1976.

30. Opiela KS, Khasnabis S, Datta TK. Determination of the characteristics of bicycle traffic at urban intersections. Transportation Research Record. 1980;743:30-8.

31. American Association of State Highway and Transportation Officials. Guide for Development of Bicycle Facilities. $4^{\text {th }}$ ed. Washington, DC: American Association of State Highway and Transportation Officials; 2012

32. Federal Highway Administration. Manual on Uniform Traffic Control Devices for Streets and Highways. 2009 Ed. Washington, DC: U.S. Department of Transportation; 2009.

33. Hou Y, Sun C, Edara P. Statistical test for 85 th and 15 th percentile speeds with asymptotic distribution of sample quantiles. Transportation Research Record. 2012 Jan; 2279(1):47-53.

34. Figliozzi MA, Glick TB. Evaluation of Roadway Reallocation Projects: Analysis of Before-andAfter Travel Speeds and Congestion Utilizing High-Resolution Bus Transit Data. NITC-RR-887. Portland, OR: Transportation Research and Education Center (TREC); 2017. 